\title{
8
}
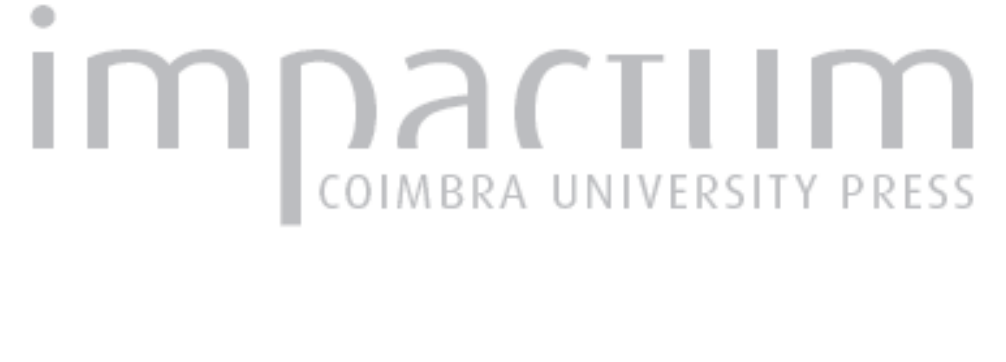

\section{A relação entre hidroelétricas e riscos em saúde: experiência vivenciada no município de Nova Ponte (MG). Brasil}

Autor(es): $\quad$ Astolphi, Joana D'Arc Vieira Couto; Silva, Vicente de Paulo da

Publicado por: Associação Portuguesa de Riscos, Prevenção e Segurança; Imprensa da Universidade de Coimbra

URL

persistente:

URI:http://hdl.handle.net/10316.2/39725

DOI:

DOI:https://doi.org/10.14195/1647-7723_23_1

Accessed : $\quad$ 26-Apr-2023 11:23:56

A navegação consulta e descarregamento dos títulos inseridos nas Bibliotecas Digitais UC Digitalis, UC Pombalina e UC Impactum, pressupõem a aceitação plena e sem reservas dos Termos e Condições de Uso destas Bibliotecas Digitais, disponíveis em https://digitalis.uc.pt/pt-pt/termos.

Conforme exposto nos referidos Termos e Condições de Uso, o descarregamento de títulos de acesso restrito requer uma licença válida de autorização devendo o utilizador aceder ao(s) documento(s) a partir de um endereço de IP da instituição detentora da supramencionada licença.

Ao utilizador é apenas permitido o descarregamento para uso pessoal, pelo que o emprego do(s) título(s) descarregado(s) para outro fim, designadamente comercial, carece de autorização do respetivo autor ou editor da obra.

Na medida em que todas as obras da UC Digitalis se encontram protegidas pelo Código do Direito de Autor e Direitos Conexos e demais legislação aplicável, toda a cópia, parcial ou total, deste documento, nos casos em que é legalmente admitida, deverá conter ou fazer-se acompanhar por este aviso.

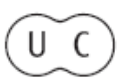




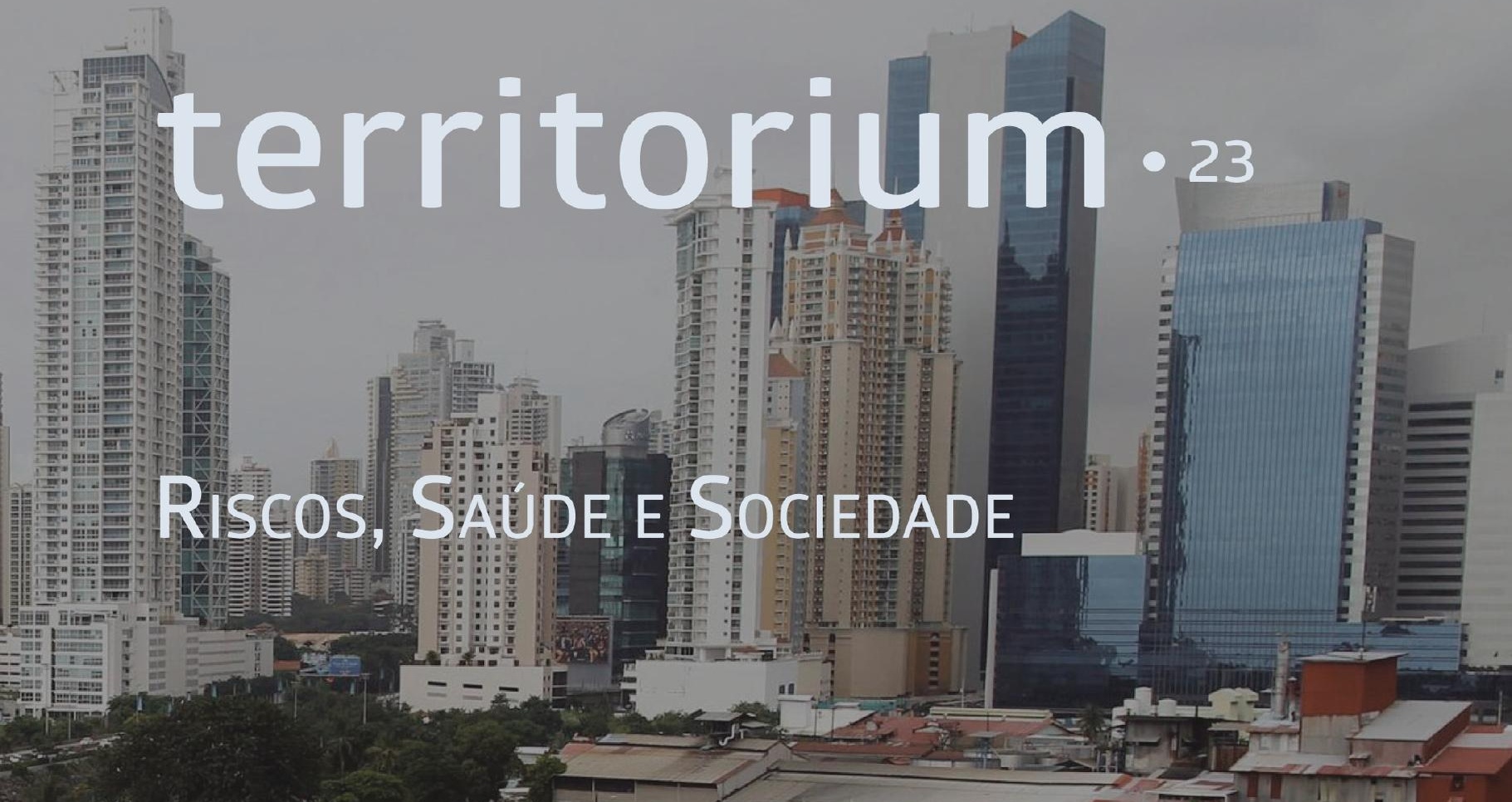

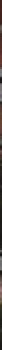

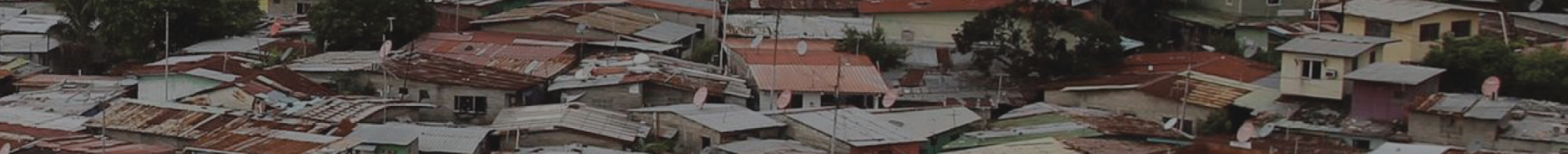

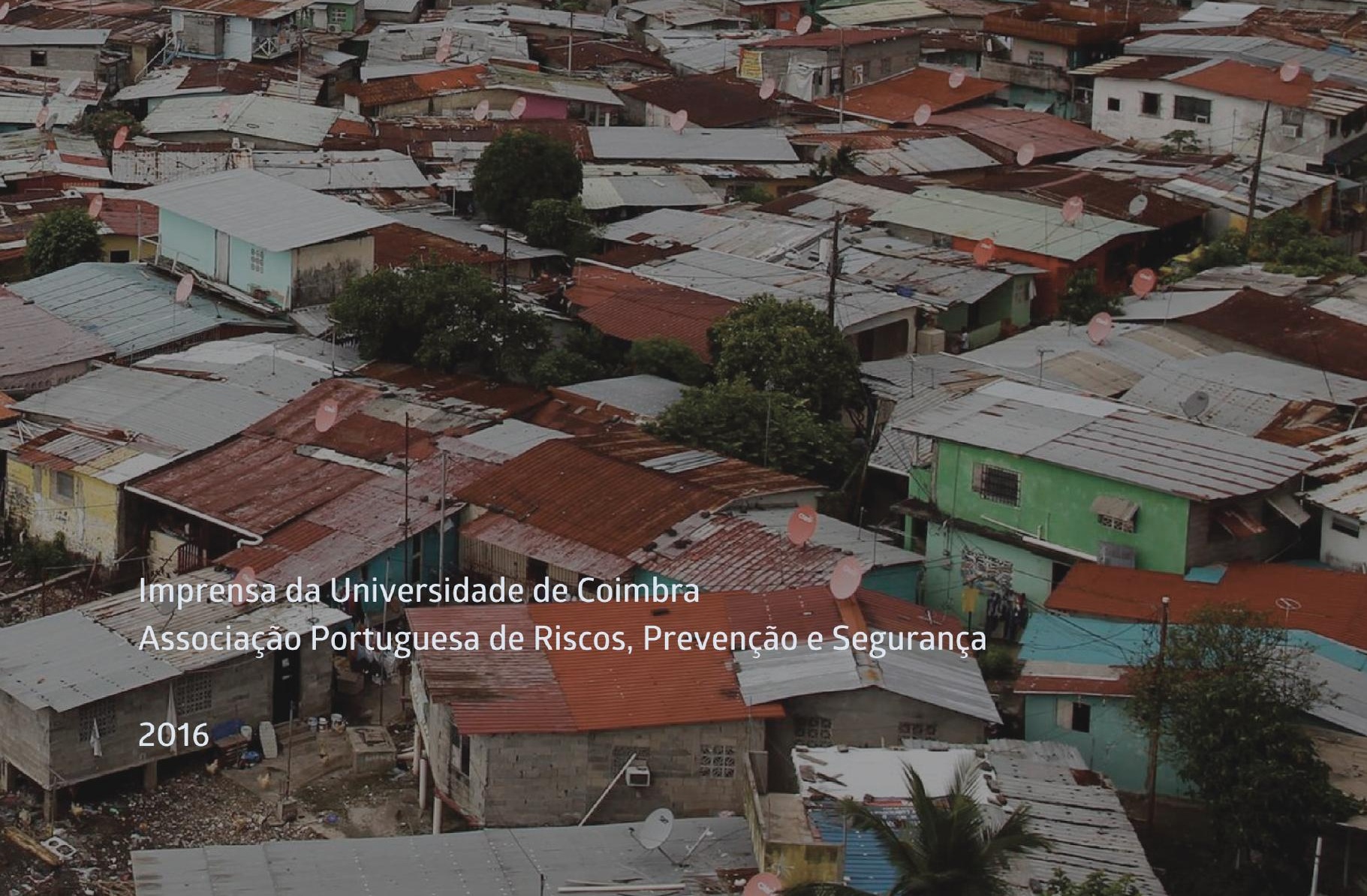




\title{
A RELAÇÃO ENTRE HIDROELÉTRICAS E RISCOS EM SAÚDE: EXPERIÊNCIA VIVENCIADA NO MUNICÍPIO DE NOVA PONTE (MG) - BRASIL*
}

THE RELATIONSHIP BETWEEN HYDROELECTRIC AND HEALTH RISKS:

EXPERIENCE IN THE MUNICIPALITY OF NOVA PONTE (MG) - BRAZIL

\author{
Joana D'Arc Vieira Couto Astolphi \\ Instituto de Geografia, Universidade Federal de Uberlândia \\ jastolph@terra.com.br \\ Vicente de Paulo da Silva
}

Instituto de Geografia, Universidade Federal de Uberlândia vicentepht@hotmail.com

\section{RESUMO}

O objetivo deste trabalho é compreender as relações existentes entre os Grandes Projetos de Investimentos (GPIs), na forma específica de hidroelétricas e os riscos em saúde, especialmente os riscos voltados para o aparecimento de novas doenças. Os resultados revelam uma estreita relação entre morador e território usado, na medida em que algumas doenças podem estar relacionadas com as alterações sofridas no contexto de vida das pessoas.

Palavras-chave: Grandes Projetos de Investimentos, risco, doenças, cidade.

\section{ABSTRACT}

This paper aims to understand the relationship between the Great Investment Projects (GPI), the specific form of hydroelectric and health risks, especially the risks of new diseases. The results reveal close relationship between the resident and the territory used, as some diseases can be related to changes of the people's life context.

Keywords: Large Investment Projects, risk, diseases, city.

\section{RESUMEN}

La relación entre la energía hidroeléctrica y los riesgos de salud experimentados en el municipio de Nova Ponte (MG) - Brasil - El objetivo de este estudio es comprender la relación entre los proyectos de gran inversión (GPI), en la forma específica de producción de energía hidroeléctrica, y los riesgos para la salud, especialmente de los riesgos que resultan en la aparición de nuevas enfermedades. Los resultados revelam la estrecha relación entre residentes y territorio utilizado, en la medida en que algunas enfermedades pueden estar relacionados con los cambios sufridos en el contexto de la vida de las personas.

Palabras clave: Grandes proyectos de inversión, riesgo, enfermedades, ciudad.

\section{RESUMÉ}

La relation entre les risques hydroélectriques et la santé : l'expérience de la ville de Nova Ponte (MG)(Brési) - L'objectif de cette étude est de comprendre la relation entre les grands projets d'investissement (GPI), l'aspect spécifique de l'industrie hydroélectrique, et les risques de santé, en particulier les risques qui pèsent sur l'émergence de nouvelles maladies. Les résultats révèlent une relation étroite entre les résidents et le territoire utilisé, dans la mesure où certaines maladies peuvent être liées aux changements du cadre de vie.

Mots-clé: Grands Projets d'Investissement, risqué, maladies, ville.

* O texto deste artigo corresponde a uma comunicação apresentada no III Congresso Internacional, I Simpósio Ibero-Americano e VIII Encontro Nacional de Riscos, tendo sido submetido em 27-11-2015, sujeito a revisão por pares a 18-03-2016 e aceite para publicação em 31-03-2016.

Este artigo é parte integrante da Revista Territorium, $n .{ }^{\circ} 23,2016,{ }^{\circ}$ RIscos, ISSN: 0872-8941. 


\section{Introdução}

Os Grandes Projetos de Investimentos (GPIs) indubitavelmente têm promovido profundas transformações no território, à medida que destroem modos de vida tradicionais ou mesmo pelas mudanças perceptíveis na própria paisagem. No caso dos empreendimentos hidrelétricos, por vezes, o deslocamento compulsório tem sido considerado um dos efeitos mais invasivos dessa decisão por grandes empreendimentos. Essa opção poderá influenciar no processo saúde-doença de moradores submetidos a este processo de "desterritorialização", conforme termo utilizado por R. Haesbaert (2004).

O processo identificado como desterritorialização, significa a perda ou o desaparecimento dos territórios e envolve uma trama mais ampla, ou seja, a complexidade da multiterritorialidade expressa nos fenômenos de (re) territorialização ou ainda a des(re)territorialização. Para tanto, o tema sugere o entendimento de território e territorialidade, considerando que qualquer acepção, será permeada pelo poder, este não apenas ligado ao tradicional, "poder político", mas remete tanto ao poder no sentido mais concreto, funcional e do valor de troca, de dominação, quanto ao poder no sentido mais simbólico, de apropriação, tenebroso pelas marcas do "vivido" e do valor de uso como nos aponta R. Haesbaert (2004).

As mudanças que ocorrem no território ocupado pelos GPIs, influenciam no processo saúde-doença, econsequentemente no perfil epidemiológico dos moradores. Da mesma forma também podem suscitar sentimentos de desterritorialidade expressos em mudanças simbólicas como nas relações de compadrio e vizinhança, alteração na produção econômica, na relação com a terra e com o rio, além de perda do espaço para produção na várzea, dentre outras. Em casos em que o uso do território exige a construção de um novo espaço de morada para os habitantes do lugar a insatisfação pode ainda levar ao abandono do novo território porque não há afetividade, ou seja, os empreendedores não consideram esses riscos no processo de transferências das pessoas de um lugar para o outro, pois, isso implicaria num atraso na execução da obra e, provavelmente, mais recursos a serem despendidos para garantia da mesma.

A territorialidade, além de incorporar uma dimensão estritamente política, diz respeito também às relações econômicas e culturais, pois está intimamente ligada ao modo como as pessoas utilizam a terra, como elas próprias se organizam no espaço e como elas dão significado ao lugar conforme concebido por R. Haesbaert (2004).

Entender o território como uma construção social produzida na relação entre os sujeitos sociais e o lugar, contextos sociais estes que favorecem a saúde ou a doença, nele incluso a questão dos riscos em saúde, é fundamental para a contextualização do elemento humano enquanto sujeito da ação.
Ao pensar nos efeitos sociais dos grandes empreendimentos, as transformações que causam no território e, partindo do entendimento da dimensão territorial, enquanto espaço de construção, entendese que esse território gera nas pessoas sentimentos de reconhecimento e pertencimento que constituem a própria identidade. Decorrente dessa relação, poderá se formar um espaço suscetível à produção da doença no contraponto da produção da saúde.

O objetivo desse trabalho é compreender as relações existentes entre os GPIs, na forma específica de hidrelétricas, associado aos riscos à saúde, especialmente os riscos voltados para o aparecimento de novas doenças.

A problemática que inquieta os pesquisadores é compreender o quanto a implantação de um grande projeto de investimento, em especial, aquele que leva ao deslocamento compulsório de uma população do lugar tradicional de vida, poderá suscitar o aparecimento de novas doenças relacionadas à questão de perda do lugar e, no reverso, a insatisfação que leva ao sentimento de não pertencimento ao novo.

O olhar investigativo repousa na complexidade das relações estabelecidas entre o espaço vivido, os atores (moradores, empreendedores e gestores) que o concretizam, as interações desencadeadas e possíveis associações com o processo saúde-doença da população de Nova Ponte, região do Triângulo Mineiro, Estado de Minas Gerais. Espera-se que este estudo possa fornecer dados relevantes e corroborar com outras pesquisas sobre o tema ampliando com isso o conhecimento nesta área.

\section{Material e Métodos}

A pesquisa de campo, para coleta de dados de fonte primária, foi trilhada com base nos métodos das ciências sociais, que classifica em dois grupos "o dos que proporcionam as bases lógicas de investigação científica e o dos que esclarecem acerca dos procedimentos técnicos que poderão ser utilizados" (A. C. Gil, 1999, p. 27).

Trata-se de um estudo com abordagem quantitativa e qualitativa. Estas abordagens foram escolhidas pela complexidade e subjetividade do objeto de estudo, já que estas "permitem o descobrimento ou aprofundamento de processos sociais, pois trabalha com o universo de significados, valores e atitudes" (M. C. S. Minayo, 2007, p. 108).

Dessa forma, procedeu-se a um levantamento de dados secundários nos sistemas de informação oficiais; seleção da amostra dos sujeitos de pesquisa baseado em critérios pré-definidos; uso do termo de consentimento livre e esclarecido; realização de entrevistas, tratamento dos dados coletados e análise quantitativa e qualitativa.

Com relação as entrevistas foram realizadas um total de 139 entrevistas, sendo 110 com moradores, 25 com 
profissionais de saúde e 4 com gestores, no período de março a agosto de 2014. Utilizou-se da entrevista estruturada com seis perguntas abertas com o objetivo principal de avaliar sob o ponto de vista dos entrevistados o processo de saúde-doença frente as alterações suscitadas no território com a implantação de hidroelétrica.

Os resultados e respectivas análises foram demonstrados de forma quantitativa (gráficos) e qualitativa (fragmentos de relatos), esta última na forma de análise de conteúdo temática.

Em Minayo (2007) os tipos de abordagens e os dados provenientes da quantitativa (estatística) e da qualitativa (significados) não são incompatíveis, o que existe é uma oposição complementar, possível de alcançar bons resultados quando trabalhadas na teoria e na prática de forma adequada.

\section{Grandes projetos hidrelétricos e riscos à saúde}

Baseado em Vainer e Araújo (1992), os GPIs constituem empreendimentos que materializam o processo de apropriação de recursos naturais e humanos em determinados lugares do território, na lógica predominantemente economicista, para responder a determinações e acepções conformadas em espaços relacionais externos aos das populações e regiões dos arredores dos empreendimentos.

O discurso da modernização e do desenvolvimento atribuído aos grandes projetos hidrelétricos traz no seu bojo um ideal de igualdade e de benefícios a todos, porém, é preciso atenção aos símbolos inerentes ao discurso dominante. Quando dizem que as hidrelétricas vêm trazer, para um país ou para uma região, a esperança de salvação da economia, da integração no mundo, a segurança do progresso, tudo isso "são símbolos que permitem aceitar a racionalidade do objeto que, na realidade, ao contrário, pode exatamente vir destroçar a nossa relação com a natureza e impor relações desiguais" (M. Santos, 1999, p.173).

A evolução da questão energética no Brasil sinaliza que, ao lado de determinantes técnicos, existe uma dimensão econômica e institucional que define a formação do setor energético, com a configuração que se apresenta na atualidade. O desenvolvimento do setor depende, conforme Calabi et al. (1983) do processo interacional dos elementos: o movimento geral da economia, a presença do Estado como ordenador setorial e a ação das empresas produtoras e distribuidoras de energia.

Nesta engrenagem é preciso lembrar o papel de outros agentes da indústria da energia, tais como: empresas construtoras e fornecedoras de equipamentos e suprimentos, bem como as empresas de consultorias que detém, muitas delas, o domínio da informação necessária à determinação de um empreendimento. Vainer e Araújo (1992) apontam como isto ocorre também com o consumidor de energia, principalmente aquelas indústrias energointensivas que gozam de benefícios tarifários. Com isso, forma-se a teia construída em torno dos interesses fundamentalmente econômicos e políticos que permeiam os GPIs.

Midiaticamente é anunciado progresso para a região e a inserção da mesma na modernidade, quase sempre limítrofe ao próprio empreendimento, "assemelhando aos tradicionalmente conhecidos 'enclaves coloniais', tais enclaves inseridos no território, não emergem de seu processo de desenvolvimento, portanto, não apregoam as forças internas de cunho socioeconômico e político" (C. B. Vainer e F. G. B. Araújo, 1992, p.34).

Os grandes empreendimentos são definidos por alguns autores apenas como projetos de Usinas Hidrelétricas de grandes dimensões. No entanto, a definição de Martins (1993) torna o termo mais abrangente. Os grandes projetos se referem aos projetos econômicos de envergadura. Como exemplos as hidrelétricas, rodovias, planos de colonização, de grande impacto social e ambiental que, como afirma o autor, embora esses projetos não tenham por destinatárias as populações locais, "seu pressuposto é o da remoção dessas populações”, mesmo que este pressuposto seja inconfessável, ele é acionado, na medida em que a população represente algum obstáculo para a implantação dos grandes projetos governamentais (J. S. Martins, 1993, p.61-62).

Cabe citar outros exemplos de GPIs, segundo Vainer e Araújo (1992), a construção de rodovias, como a Transamazônica, no caso brasileiro, a implantação de usinas nucleares de Angra I e Angra II, construção de um edifício, um aeroporto, introdução da cana-de-açúcar em áreas destinadas ao plantio de alimentos, dentre outros, como projetos de grandes dimensões.

A produção de energia é importante para o desenvolvimento e isto é inegável, porém, é preciso refletir, afinal estamos nos referindo ao desenvolvimento de quem, de que, e para quem. Tais indagações ajudam no sentido de desnudar o conteúdo no plano do discurso e o que realmente restará em termos práticos, ao longo do tempo, a população para a qual se destina.

O Brasil se encontra com uma questão crucial em relação "à produção de energia utilizando de fontes renováveis, neste caso, a energia hidrelétrica se enquadra, porém com impactos ambientais negativos, decorrentes em especial da migração desordenada e do desmatamento, estes passíveis de diminuição na etapa de planejamento" (B. K. Becker, 2012, p.785).

A iminência dos empreendimentos hidrelétricos nos locais mais diversos do país desperta sentimentos variados na população a ser afetada pelo projeto de execução de uma barragem, gerando desencontros, estranhezas e suscitando crenças produzidas pelos empreendedores 
(agentes imediatos do capital) ao dispor de recursos (financeiros, midiáticos, estruturais) para demonstrar uma realidade que justifique a construção, isto corroborado, pelos agentes do governo, sob o lema do desenvolvimento regional/local.

O estudo proposto por Martins (1993) colabora com a análise não apenas da história dos dominados, mas também, do "invasor de terras e tribos", aquele que expulsa os camponeses, quebra linhagens de família, destrói relações sociais, que, segundo esse autor, clandestina as concepções culturais, valores e regras.

Sobre o impacto do estranho, afirma que: “[...] $a$ devastação da floresta destrói [...] espécies vegetais úteis [...] mutilação de grupos sociais suprime modos de viver e de pensar [...] destrói saberes que representam um germe de alternativas para a desumanização acelerada que estamos vivendo" (J. S. Martins, 1993, p.12).

Vainer e Araújo (1992) fazem uma análise para além dos impactos, direcionada para os efeitos para a região e o local, onde implantam grandes projetos, a partir de uma lógica inflexível impetrada pelo interesse setorial/ nacional em detrimento do reconhecimento das particularidades do espaço regional/local.

A escolha, pelo termo efeito, ao invés de impacto, "é por entender que com ele caracterizamos melhor as mudanças advindas da execução de um empreendimento, pois sugere uma abrangência e uma durabilidade maior no tempo e no espaço" (V. P. Silva, 2013, p.111).

Antes mesmo de falar dos efeitos trazidos pelos GPIs, cabe ressaltar que os empreendimentos são na verdade ferramentas ativas do (re) ordenamento territorial, mesmo que isso não seja explicitado no seu planejamento.

Os grandes projetos afetam e transformam o território, utilizando o discurso da produção de energia através de fontes renováveis e da garantia de ações compensatórias para a população atingida pela barragem. O deslocamento compulsório de moradores, parte fundante da concretização destes projetos, conduzirá a uma problemática territorial complexa que evidencia o volumoso contingente de expropriados das áreas determinadas para o fim projetado. Martins (1993) ajuda a refletir sobre esta questão ao sinalizar que os projetos são de grande magnitude econômica, envolvendo investimentos em setores da economia voltados, principalmente à infraestrutura. Em função da apropriação de determinada posição do espaço geográfico, estes empreendimentos não geram, efetivamente, uma melhora na qualidade de vida (de forma integral) da totalidade da população que os recebem.

O território pode ser negativamente afetado pela ação dos grandes projetos. A apropriação e uso desses espaços muitas vezes colocam em pontos extremos os responsáveis pela construção de grandes obras e os moradores que ocupam áreas de interesses desses empreendedores.

Os grandes projetos podem ser entendidos como aqueles que mobilizam capital, força de trabalho, recursos naturais, energia e território, em grande escala. Dentre os grandes empreendimentos, temos a construção de usinas hidrelétricas, que modificam consubstancialmente o cenário socioambiental e cultural das populações nele inserida.

A situação inicialmente vivenciada pelo morador é estrategicamente pontual, por exemplo, o morador recebe indenização pela casa inundada e ainda consegue emprego na obra, cujo salário supera dos trabalhos antecessores, com isso, as pessoas perdem a noção do caráter temporário do emprego, conforme a execução da obra, e do respectivo ganho financeiro.

De fato, nas regiões e locais submetidos aos empreendimentos, de certa forma, ao final das contas, tem ficado a desestruturação das atividades econômicas existentes a priori, o crescimento caótico da população, a geração de desemprego entre nativos e imigrantes, potencialização de realidades sociais tais como: marginalidade, criminalidade, violência, mendicância, dentre outras e, sobretudo degradação do meio ambiente.

Neste cenário de miserabilidade das populações, em espaços urbanos não equipados, os poderes das esferas municipal e estadual, sofrem com a avalanche de problemas na ordem de educação, saúde, habitação, saneamento básico, pois já não existem mais a mola propulsora do desenvolvimento existente no bojo do empreendimento e o poder de barganha dos municípios, do Estado e da região se veem vulneráveis, mesmo com o crescimento da arrecadação (no caso dos royalties), pois subsídios e benefícios fiscais ofertados às empresas impactaram este montante.

Desta forma, os enclaves gerados não se restringem a questão socioeconômica, se estendem a questão política, diminuindo a capacidade gestora e decisória autônoma regional/local, na medida em que se veem capturados pela lógica e estruturas de poder decisório do âmbito setorial/nacional.

Em Raffestin (1993) é realçado o caráter político do território, incluindo os processos econômicos e simbólicos do sistema territorial, enfatizando as relações de poder e as redes de circulação e comunicação. Esse autor, concebe o sistema territorial, como resultado das relações de poder do Estado, das empresas e outras organizações e dos indivíduos, relações estas permeadas pelo binômio: poder e dominação.

Quanto às relações de poder acima mencionadas, é possível inferir que, a execução de grandes projetos, pode materializar o caráter político do poder em relação ao 
território, com a execução do empreendimento, a partir da submissão da população local diante da remoção, ou melhor, dizendo, do deslocamento compulsório.

Vale ressaltar que em relação às metas traçadas pelos GPIs, como exemplo, a geração de eletricidade programada pelas hidrelétricas, o balanço é positivo, no entanto, a reboque fica a economia regional/local, onde houve implantação do empreendimento, havendo um desiquilíbrio de forças, de interesses e de necessidades, prevalecendo os pressupostos do setorial/nacional.

Os efeitos provocados pelos empreendimentos hidrelétricos já instalados, como é o caso da Usina Hidrelétrica (UHE) de Nova Ponte são perceptíveis. Embora, o histórico das construções de UHE demonstre que nenhuma dessas obras atende ao que é preconizado pela legislação ambiental, a sua implantação é referida pelos documentos oficiais, que tenha ocorrido dentro das normas da legislação ambiental do Brasil, isto, porém, não impediu de provocar efeitos de caráter social e físico-biológicos no local de instalação (Cemig, 1995).

A construção da UHE de Nova Ponte foi demarcada por aspectos sociais e impactos físico-biológicos, de grande relevância, tais como: “[...] 1.152 propriedades rurais foram parcial ou totalmente inundadas [...] deslocamento da população urbana de Nova Ponte, cerca de 5.000 pessoas para uma nova cidade planejada a três quilômetros [...] contingente populacional de 9.000 pessoas [...] impactos físico-biológicos, o período mais grave foi o da construção da barragem [...] desmatamento, obras de escavação e terraplanagem, disposição dos rejeitos de construção, montagem de canteiro de obras [...] processos erosivo das margens [...] devido ao rebaixamento do reservatório" ( $F$. B. Silva, 2007, p.84).

Consoante a Lima e Silva (2011) o aproveitamento hidrelétrico, enquanto fonte de energia renovável atinge diretamente tudo o que é estabelecido sobre o território de um determinado lugar à medida que as barragens das usinas hidrelétricas inundam áreas e nelas a fauna e a flora.

Há que se considerar também, toda a ordem da cultura humana é profundamente afetada pelo impacto, ou seja, pelo efeito sócio espacial de suas construções. Desta forma, o território em reconstrução aparece marcado pelos efeitos dos deslocamentos populacionais, provocados pela execução de grandes empreendimentos hidrelétricos.

A contradição existente no discurso e na prática dos empreendimentos (setorial/nacional) que afetam a região e o local evidencia a ambiguidade presente no Setor Elétrico, quando: "[...] o SE simultaneamente reforça um padrão de desenvolvimento e tenta apresentá-lo como natural e inevitável, aprofunda as desigualdades regionais e anuncia sua preocupação em preservar os interesses das regiões impactadas pelos grandes aproveitamentos hidrelétricos" (C. B. Vainer e F. G. B. Araújo, 1992, p.59-60).

$\mathrm{Na}$ inclusão da questão dos riscos neste debate, torna-se necessário o entendimento da problemática. Na lógica do desenvolvimento, sob a égide da exploração dos recursos naturais, existem riscos que vem a ser: " $A$ 'maldição da abundância' é uma expressão usada para caracterizar os riscos que correm os países pobres onde se descobrem recursos naturais objeto de cobiça internacional. A promessa de abundância decorrente do imenso valor comercial dos recursos e dos investimentos necessários para concretizá-lo é tão convincente que passa a condicionar o padrão de desenvolvimento económico, social, político e cultural” (B. S. Santos, 2012, p.1).

O risco definido como uma construção social pressupõe ir além da objetivação do processo, e considerar a percepção e a subjetivação do homem nas relações cotidianas. Conforme Veyret (2007, p.24), o risco é "uma construção social. A percepção que os atores têm de algo que representa um perigo para eles próprios, para os outros e seus bens, contribui para construir o risco que não depende unicamente de fatos ou processos objetivos".

A noção de risco, tanto do "perigo potencial", quanto da "percepção", sinaliza uma situação apreendida como ameaçadora, na qual se está incluso diretamente ou sentindo os seus efeitos. O contexto histórico na construção do risco se justifica pelo fato de que a prevenção e a proteção contra os riscos não poderá ser abarcada alheia a uma dimensão temporal. Neste sentido, o território estabelece relações variadas com os riscos (naturais, tecnológicos ou sociais) de acordo com a época e com a cultura, na perspectiva da temporalidade.

O risco hoje assume o sentido positivo, quando vislumbra obter bens comuns e pessoais almejados, isto do ponto de vista da economia nos sistemas liberais. O risco nasce da percepção de um acontecimento possível que poderá comprometer um sistema e ainda sinaliza os indicadores de vulnerabilidade, que carrega no seu bojo aspectos físicos, ambientais, psicossociais, socioeconômico, técnicos e políticos também.

Em conformidade com Veyret (2007) os riscos econômicos, geopolíticos e sociais, estão associados a recursos, renováveis ou não, gerando riscos evidenciados por conflitos ocultos ou escancarados, no caso da reserva de água, que remete a sua gestão, motivados pelos aspectos da escassez de água, da piora nas condições sanitárias, da produção alimentar e da população atingida.

Para entender a expressão "risco social", é preciso conceber a diversidade de atores envolvidos, a polissemia permite qualificar a maior parte dos riscos, relacionada às causas sociais e/ou as consequências humanas. 
A caracterização dos riscos sociais exógenos e dos riscos sociais endógenos corrobora para o entendimento da sua dimensão e alcance ao afetar as sociedades humanas. Baseado em Veyret (2007) os riscos sociais exógenos são os elementos naturais e as ameaças externas (inundações, secas, epidemias, etc.), por sua vez, os riscos sociais endógenos são crescimento urbano, industrialização, tipos de povoamento, densidade exacerbada de bairros, entre outros.

Desta forma, ao refletir sobre as dimensões multifacetárias (sociais, físicas e políticas) que envolvem os grandes empreendimentos, fica evidente a importância do estudo acerca dos riscos em especial, os riscos a saúde, seja pela ótica dos fatores desencadeantes ou na determinação das condições que cercam as ações de caráter emergencial.

No campo da saúde, um dos indicadores utilizados para definir recursos financeiros e ações de promoção, prevenção e recuperação da saúde, é de composição multifacetária de riscos, qual seja o Índice de Desenvolvimento Humano (IDH), cujos indicadores: esperança de vida ou mortalidade infantil, indicam aspectos de vulnerabilidade social. Neste caso, o baixo IDH constituirá um dos fatores de vulnerabilidade social e indicará investimentos socioeconômicos e políticos para a sua reversão.

$\mathrm{Na}$ discussão de riscos e saúde, os efeitos negativos referem-se à perda de bens, a morte e a doença. No tocante a poluição atmosférica, é preciso ter modelos que apresentam as relações dose-efeito, os indicadores precedentes de efeitos e os efeitos de curso crônico. Quanto à saúde e riscos alimentares estão relacionados aos elementos: qualidade dos produtos consumidos, insuficiência alimentar, saúde e droga.

Para compreender os riscos a saúde e o processo de adoecimento desencadeado, em especial da população submetida ao deslocamento compulsório em função da inundação de toda a área urbana do município para a formação do lago da UHE, foi preciso capturar o entendimento sobre riscos em saúde, no campo da epidemiologia.

O vocábulo 'risco' no Dictionary of Epidemology, faz alusão à probabilidade de ocorrência de um evento (mórbido ou fatal) e também funciona como um termo não técnico que inclui diversas medidas de probabilidade quanto a desfechos desfavoráveis. (J. M. Last, 1989).

Segundo Castiel et al. (2010) a questão de probabilidade pode ser entendida pelo prisma do intuitivo, subjetivo, vago, do campo da "incerteza que não se consegue medir" ou do objetivo, racional, mensurável, do campo da "incerteza capaz de ser medida". A abordagem dos fatores de riscos (predição de morbimortalidade) respaldada pelo segundo prisma é que possibilita intervir preventivamente junto aos indivíduos, grupos populacionais e comunidades no tocante aos fatores de risco. "O conceito de risco é, portanto, usado em epidemiologia como uma forma de compreender e medir a probabilidade de ocorrência de agravos à saúde". (L. D. Castiel et al., 2010, p.38).

Na perspectiva de compreender a dinâmica das relações entre os atores sociais envoltos na questão dos grandes projetos e os riscos à saúde, é importante considerar os interesses antagônicos, o saber local e a dimensão expandida de saúde.

A contribuição de Porto e Finamore (2012) corroboram ao afirmar que: "A partir de uma visão ampliada de saúde são discutidos os limites das abordagens cientificas em reconhecer a importância do saber local, seja para analisar riscos ambientais ou seus efeitos à saúde, incluindo os estudos epidemiológicos. Tais limites relacionam-se basicamente ao ocultamento de conflitos e incertezas, à falta de contextualização da exposição aos riscos e efeitos sobre a saúde, assim como às dificuldades de diálogo com as comunidades [...] nesses contextos, problemas de saúde e ambiente são compreendidos no interior de conflitos ambientais que expressam disputas entre, de um lado, interesses das comunidades, organizações e movimentos sociais aliados e, de outro, agentes sociais beneficiados por atividades econômicas e produtivas as mais diversas tais como: mineração, exploração e refino de petróleo, produção de ferro e aço, construção de hidrelétricas [...]" (p. 1493-1494).

Em relação ao campo da saúde pública, os riscos e seus efeitos na saúde dos indivíduos e dos grupos populacionais podem ser tratados a partir do nexo causal ou epidemiológico. Este se refere, conforme Porto e Finamore (2012) ao estabelecimento de associações baseadas em dados empíricos entre uma doença e a exposição a determinados riscos, nos ambientes cotidianos das pessoas.

Para tanto, nas ciências biomédicas, existem duas formas importantes de fazer a associação entre exposição aos riscos ambientais ou fatores de risco, para a saúde individual e para a saúde coletiva quando se argumenta que: "Do ponto de vista individual, pessoas e situações específicas são avaliadas pela medicina clínica, na qual especialistas ou peritos podem estabelecer o nexo causal a partir da existência de um forte conjunto de evidências associadas às características do histórico da exposição ocupacional/ambiental e dos sintomas clínicos, com o apoio de outros profissionais. Outra [...] são os estudos epidemiológicos em que as associações são realizadas para conjuntos de populações expostas a partir de diversas bases de dados, em particular de morbidade ou mortalidade" (M. F. S. Porto e R. Finamore, 2012, p.1496).

Dessa maneira, a Geografia percebe o espaço como uma distribuição de fatores de riscos, ambientais, 
sociais, econômicos e culturais. Em particular, o aspecto da saúde, poderá sinalizar consequências da desterritorialização, provocada pelos deslocamentos compulsórios, indicados pela inundação de áreas para atender as necessidades dos projetos de aproveitamento hídrico, seja construção de UHE e/ou Pequenas Centrais Hidrelétricas (PCHs), para produção de energia limpa, parte integrante dos GPIs.

\section{Usina hidrelétrica de Nova Ponte e os riscos à saúde}

O município de Nova Ponte, no qual foi executado o empreendimento hidrelétrico com o mesmo nome, faz parte da microrregião de Uberlândia/Araguari e da macrorregião de Uberlândia, definido no Plano Diretor de Regionalização da Saúde do Estado de Minas Gerais.

O referido munícipio, mediante a construção da UHE, deparou-se com o uso do território ligado as mudanças substanciais, que em especial atingiram a população do meio rural e os moradores da cidade, mediante o deslocamento compulsório provocado pelo empreendimento hidrelétrico.

Os moradores de Nova Ponte, submetidos ao deslocamento compulsório, egressos do meio rural e/ou da cidade velha, na dimensão do uso do território, integra o objeto de estudo da Geografia e da Saúde Coletiva, relativo ao processo saúde-doença, resultante do modo de vida imposto pelo grande empreendimento hidrelétrico.

A população procedente tanto do meio rural quanto do urbano sofre estes efeitos, mas não são necessariamente passivos, ao contrário, trata-se da existência de sujeitos ativos e dinâmicos, que lutam pelo reconhecimento de direitos.

Os moradores submetidos ao deslocamento compulsório, seja pela inundação das terras produtivas ou da cidade velha, experimentam no território "vivido" novas territorialidades como "continuum" de um processo de dominação e/ou apropriação, pelos grandes empreendimentos hidrelétricos.

Diante do exposto, é preciso pensar sobre a existência de uma relação entre o território usado, com a implantação da hidrelétrica e os riscos a saúde associada ao deslocamento compulsório da população local.

A saúde enquanto política pública é traçada na lógica da promoção, da prevenção e da recuperação, com o intuito de elevar a qualidade de vida da população, numa perspectiva multidisciplinar e multisetorial, priorizando situações e grupos vulneráveis e em situação de riscos. Contudo para entendimento pleno de seu significado e representação sociocultural faz-se necessário, principalmente, reconhecer o espaço/território, segundo a lógica das relações entre condições de vida, ambiente e acesso às ações e aos serviços de saúde.
No Brasil, a exemplo do que ocorre em outras nações, levantamentos epidemiológicos, com dados de morbidade e mortalidade da população, realizados em diversos segmentos da sociedade demonstram que o processo de saúde-doença, é influenciado por questões da ordem sócio-econômica-cultural e ambiental.

No mundo atual, há muitos sinais de manipulação de territórios que são transformados ou mesmo destruídos, em função da execução desses grandes projetos. É, por exemplo, o caso das hidrelétricas, cuja formação dos reservatórios exige a inundação de extensas áreas, rurais e urbanas e, consequentemente, a destruição dos lugares. Vivência esta que se aplica ao município foco deste trabalho, que foi construída uma nova cidade, ou seja, um novo território, para realocar a população que foi totalmente atingida pelo empreendimento.

A mobilidade espontânea dentro do movimento de migração permite que se criem novos territórios. Entretanto, o lugar antigo ou que tenha passado por um processo de transformação, terá, por certo tempo, um significado para aqueles que o viveram. A vida das pessoas submetidas à mudança de território de forma compulsória afeta e é afetada pelo processo e podem sofrer os efeitos nas suas condições de saúde e adoecimento, a depender do grau de envolvimento da pessoa com seu território; o nível de apego; os laços com o lugar.

A situação apresentada poderá desencadear o surgimento de problemas de saúde que antes não eram comuns entre os moradores submetidos a esses processos, tais como depressão, problemas psicológicos, psicossomáticos, respiratórios, dependência química, dentre outras, enfim, doenças cuja incidência pode estar diretamente relacionada com o fato de deslocarem as pessoas de suas moradias, ou mesmo por exposição a resíduos tóxicos oriundos de práticas usadas na execução das obras. Ainda, é preciso considerar o fato de que a escassez de pescado a jusante ou a montante das barragens indica mudança alimentar, caso o reassentamento seja à beira do rio. Caso contrário, a mudança alimentar ou mesmo a perda de autonomia na produção de alimentos introduz vulnerabilidade alimentar.

Promover o diálogo entre a Geografia e a saúde (risco associado ao processo de saúde-doença) da população submetida ao deslocamento compulsório, requisita a inserção da saúde coletiva e sua organização enquanto política de saúde pública.

A dimensão do coletivo conforme Nunes (1994) é reconhecidamente fato e acontecimento, que resulta de um caminho que encontre na epidemiologia, de um lado, e nas ciências humanas, de outro, as bases para constante construção de seu objeto. Em especial, no final da década de 1980 , no Brasil, marcado pelo movimento da reforma sanitária, imprimiram novas marcas na saúde coletiva, tanto no campo epistemológico como de suas práticas. 
De acordo com Mendes (2009), baseado na obra de Spassof (1999), a ciência de maior destaque na atenção à saúde baseada em evidência é a epidemiologia, já que essa disciplina tem como objeto o estudo de condições ou doenças em relação as populações ou a grupo de população.

$\mathrm{Na}$ tentativa de definir o termo epidemiologia, tarefa nada fácil, considerando seu dinamismo e sua complexidade, segue de maneira simplificada: "Ciência que estuda o processo saúde-doença em coletividades humanas, analisando a distribuição $e$ os fatores determinantes das enfermidades, danos à saúde $e$ eventos associados à saúde coletiva, propondo medidas específicas de prevenção, controle ou erradicação de doenças e fornecendo indicadores que sirvam de suporte ao planejamento, à administração e à avaliação das ações de saúde" (M. Z. Rouquayrol et al., 2013, p.11).

A saúde coletiva, constituída nos limites do biológico e do social, ainda continua a ter pela frente a tarefa de investigar, compreender e interpretar os determinantes da produção social das doenças e da organização social dos serviços de saúde, tanto no plano diacrônico como sincrónico da história. Ou, como apontam outros autores, a exemplo de Birman(1991), a saúde coletiva ao introduzir as ciências humanas no campo da saúde, reestrutura as coordenadas desse campo, trazendo para o seu interior as dimensões simbólica, ética e política, o que somente poderá revitalizar o discurso biológico.

A epidemiologia trabalha e considera os processos sociais como um sistema, o qual define a dinâmica dos agregados sociais e um que em particular constitui o campo sobre o qual desempenha a epidemiologia: o processo saúde-doença.

O processo saúde-doença entendido como: “[...] da coletividade [...] o modo específico pelo qual ocorre, nos grupos, o processo biológico de desgaste $e$ reprodução, destacando como momentos particulares a presença de um funcionamento biológico diferente, com consequências para o desenvolvimento regular das atividades cotidianas, isto é, o surgimento da doença" (M. Z. Rouquayrol et al., 2013, p.12).

Ao tratar do processo saúde-doença da população, é preciso compreender a diferença da medicina baseada em evidência e a saúde baseada em evidência. A primeira é focada na clínica, em indivíduos, dá suporte à decisão médica e a segunda amplia e dá condições a outros profissionais da saúde e ao usuário também, com centralidade na população ou grupos populacionais.

Nesta perspectiva é descrito como novo paradigma: “[...] medicina baseada em evidências decidir o tratamento [...] consistentes evidências científicas [...] mais benefício para o tomador de decisão- o médico, [...] e saúde baseada em evidências [...] o recurso pode dar suporte não só a médicos, mas a enfermeiros, psicólogos e demais profissionais ligados à área da saúde, como também aos pacientes [...] acesso às evidências obtidas" (P. F. C. B. C. Fernandes, 2013, p.177).

Para entender o processo saúde-doença na perspectiva do uso do território pelos grandes empreendimentos hidrelétricos e o risco a saúde, é preciso definir e conceituá-lo.

O processo saúde-doença é uma expressão usada para fazer referência a todas as variáveis que envolvem a saúde e a doença de um indivíduo ou população e considera que ambas estão interligadas e é consequência dos mesmos fatores. De acordo com esse conceito, a determinação do estado de saúde de uma pessoa é um processo complexo que envolve diversos fatores. Em concordância com os autores Lemos e Lima (2002) diferentemente da teoria da unicausalidade, muito aceita no início do século XX, que considera como fator único de surgimento de doenças um agente etiológico, o conceito de saúde-doença estuda os fatores biológicos, econômicos, sociais e culturais e, com eles, pretende obter possíveis motivações para o surgimento de alguma enfermidade.

Desta forma, a vida cotidiana, configura o lugar de manifestação das “tensões” entre os processos biológicos e sociais que determinam o estado de saúde de uma população ou grupos populacionais, de base territorial, a partir do uso do território nas dimensões - política, econômica, natural e cultural.

A abordagem fundada nos fatores de risco, associada à mudança de estilo de vida, no campo da promoção da saúde, que predominava na década de 70 , foi fortemente discutida na I Conferência Internacional de Promoção da Saúde no Canadá em 1986. A discussão resultante dos debates da conferência diz sobre a "nova promoção da saúde", que segundo Castiel et al. (2010) baseado na obra de Lupton (1995) remete ao fato de que, "apesar de considerar o risco epidemiológico, o enfoque é dado para os condicionantes (social, econômico e cultural) da saúde, desviando da ênfase "medicalização" do sistema de saúde para ações multissetoriais e políticas públicas".

A saúde e a doença são processos inerentes à vida e são condicionados pelos modos de vida e estes permeados por determinantes multifacetários evidenciando que: "[...] são expressões das características do meio natural, do grau de desenvolvimento de suas forças produtivas, de sua organização econômica e política, de sua forma de relacionar-se com o meio ambiente, de sua cultura, de sua história, de outros processos gerais que configuram sua identidade como formação social. [...] processos gerais se expressam no espaço da vida cotidiana das populações, no que se denomina modo de vida da sociedade" (P. L. Castellanos, 1998 apud P. M. Buss, 2002 p.51).

O estudo epidemiológico realizado pela Fundação Nacional de Saúde (FNS), encomendado pelo empreendedor e que integrou o estudo de viabilidade da implantação da 
UHE de Nova Ponte, demonstra certa ênfase ao processo biológico se comparado aos condicionantes socioeconômico ambiental, ao descrever que: "[...] permitiram classificar o município em padrão médio, tomando como referência - Alto Paranaíba. [...] perfil nosológico concentrado nas doenças típicas de populações rurais carentes [...] área endêmica para a doença de chagas. [...] região indene para esquistossomose. [...] área não malárica [...] zona epizóotica de febre amarela" (Cemig, 1995, p.66).

No levantamento de dados secundários, de fonte oficial, constatou-se a inexistência de base de dados oficial, para consulta e levantamento das doenças que acometiam a população no período anterior a construção da UHE de Nova Ponte e a mudança para a cidade nova ocorrida em 1994. Cabe esclarecer que o Sistema Único de Saúde (SUS) foi instituído pela Constituição Federal de 1988 , e regulamentado pela Lei $N .^{\circ} 8.080 / 1990$ e Lei n. ${ }^{\circ} 8142 / 1990$. O Ministério da Saúde (MS) implantou o Sistema de Informação Hospitalar do SUS (SIH/SUS) por meio da Portaria GM/MS n. ${ }^{\circ}$ 896/1990 (Brasil, 2010). Na implementação do SUS ocorreu a municipalização da saúde, com a descentralização e o comando único na esfera municipal, efetivado no município de Nova Ponte em meados de 1994. Por sua vez, a implantação da base de dados, como, Sistema de Informação sobre Mortalidade (SIM) e SIH/SUS, consta registros somente a partir de 1996, porém, consideramos que esse período ainda é próximo à efetivação da mudança da cidade velha para a cidade nova.

A Organização Mundial de Saúde (OMS) define um sistema de informação de serviços de saúde como aquele cujo propósito é selecionar os dados pertinentes a esses serviços e transforma-los na informação necessária para o processo de decisões, próprio das organizações e dos indivíduos que planejam, administram, medem e avaliam os serviços de saúde. Considera-se que de acordo com Brasil(2006) a transformação de um dado em informação exige, além da análise, a divulgação e as recomendações para a ação.

Desta forma, optou-se por recorrer à fonte primária, informações levantadas a partir do relato de profissional da saúde, com atuação e vivência na cidade velha de Nova Ponte e continuidade das atividades profissionais na cidade nova.

Seguem fragmentos do referido relato:

"Naquela época eram acometidos mais pelas doenças do coração (miocardiopatia chagásica); verminose; doenças de pele; hipertensão; diabetes e mais raro hepatite [...] na cidade nova morrem de infarto agudo do miocárdio; complicações da diabetes; acidentes automobilísticos [...] sofrem de doenças osteomusculares, hipertensão arterial, diabetes [...] neoplasias (câncer) de reto, de estomago, de colo de útero e de mama" (Entrevista 125).

A consulta na base de dados do SIH/SUS, relativa à morbidade hospitalar do SUS por local de internação e de residência, no período compreendido de 1998 a
2013, do município de Nova Ponte - MG possibilitou uma análise inicial da evolução das doenças que acometem a população local.

O levantamento demonstrou que de forma geral, no período de 1998 a 2013, houve aumento dos quadros de diarreia e gastroenterite, doenças do aparelho circulatório, manteve lineares quadros de desnutrição, de diabetes, de depressão e de stress e aparecimento de casos de neoplasias (1998- 2013), de septicemia (2009-2013), de doenças endocrinológicas, nutricionais e metabólicas (1998-2013) e de transtornos mentais e comportamentais (1998-2013).

\section{Discussão dos dados e resultados alcançados}

Para a coleta de informações de fonte primária, foram realizadas entrevistas, do tipo estruturada, com perguntas abertas relativas ao processo de adoecimento, à morbimortalidade da população na cidade velha e na cidade nova. Participaram da pesquisa cento e dez moradores, sendo setenta e seis egressos da cidade velha e trinta e quatro nascidos na cidade nova, ou egressos de outra localidade, ainda com vinte e cinco profissionais de saúde sendo doze egressos da cidade velha e treze profissionais nascidos na cidade nova ou egressos de outra localidade, além de quatro gestores sendo dois gestores municipais na cidade velha e dois gestores municipais na cidade nova.

As informações coletadas com os segmentos de moradores, de profissionais de saúde e de gestores municipais, em termos de doenças mais frequentes antes e depois da implantação da UHE (1994) e mudança para a cidade nova foram subsídios para a análise comparativa dos dois períodos (antes e depois) e de possíveis alterações no perfil epidemiológico, sob a ótica destes sujeitos da pesquisa.

As figuras 1 e 2 mostram os tipos de doenças encontradas na cidade velha e na cidade nova, as patologias citadas foram agrupadas por área médica acometida ou forma de contágio, por frequência e distribuídas nos segmentos dos sujeitos pesquisados.

0 índice das doenças infectocontagiosas citadas, como exemplos: febre amarela, coqueluche, sarampo, tétano, caxumba, poliomielite, varicela (catapora) e rubéola, caiu de $35 \%$ para $4 \%$. É possível associar a redução das doenças infectocontagiosas na cidade nova, com a melhora das condições sanitárias, da imunização com o aumento da cobertura vacinal e o fortalecimento da atenção primária com a estratégia de saúde da família. Ainda, nesta categoria é citada a doença de Chagas, cuja incidência está diretamente relacionada às condições de habitação, como exemplo, casas de pau-a-pique, que no caso da cidade velha de Nova Ponte era possível encontrar esse tipo de construção. As condições de moradia, aliadas 
à escassez de medidas preventivas como: conservação das casas, aplicação regular de inseticidas e uso de telas em portas e janelas, em especial em ambientes rurais, potencializava o aparecimento da doença.

Também houve redução das doenças gastrointestinais relatadas, tais como, diarreia, verminose, hepatite e esquistossomose. A redução das doenças gastrointestinais na cidade nova é provavelmente decorrente das melhorias no saneamento básico, visto que essas doenças são transmitidas pelo contato ou ingestão de água contaminada, contato da pele com o solo e lixo contaminados, dentre outras. Cerca de 20 anos atrás, ou seja, na cidade velha, a população de Nova Ponte não tinha acesso à água de boa qualidade, esgoto tratado e destino adequado do lixo.

A elevação da frequência das doenças cardiovasculares de $15 \%$ (cidade velha) para 33\% (cidade nova) poderá ser associada a hábitos de vida nocivos próprios da vida moderna. Houve o aumento da frequência das doenças neuropsiquiátricas de $4 \%$ (cidade velha) para 24\% (cidade nova), estas relacionadas ao alcoolismo e outras drogas, à depressão e ao estresse, doenças que se manifestam no comportamento individual e na vida social. Elas podem, de certa forma, estar relacionadas à mudança do núcleo urbano, com o deslocamento compulsório, as dificuldades de inserção nas atividades profissionais, o apego ao lugar antigo e o desencontro com o novo, o acesso às substâncias psicoativas e o nível de estresse, gerado pela competividade, própria da vida nos núcleos urbanos.

A morbimortalidade por causas externas passou de $2 \%$ (cidade velha) para 6\% (cidade nova), e tem possível associação com a localização geográfica da cidade nova próxima da rodovia. Os acidentes de trânsito sejam na rodovia ou na cidade, alinhados ao consumo de álcool e outras drogas podem contribuir para a elevação desse número.

Além disso, as condições do relevo também podem ser colocadas como causa na diferença entre esses números, ou seja, a cidade nova apresenta um relevo mais plano que a cidade velha, a qual se localizava na encosta do rio. As ruas e avenidas planas e razoavelmente largas favorecem maior incidência no uso de motos e bicicletas, que não eram comuns na cidade velha, mas também favorecem o excesso de velocidade e, consequentemente, maior número de acidentes.

0 grupo das neoplasias (Câncer) variou de 2\% (cidade velha) para 13\% (cidade nova). Entretanto, não foi possível fazer qualquer correlação entre esse grupo e a mudança das cidades. Isso ocorreu porque o simples relato de câncer, não está associado à especificidade; isto é, não sabemos o tipo e a localização desse câncer. Portanto, não podemos correlacioná-lo com mudanças geográficas.

Ainda assim, apesar de ser um comportamento percebido a nível nacional, há quem acredite que as mudanças de hábitos - como comer alimentos, preferencialmente, colhidos do quintal na cidade velha, o sossego que ela oferecia aos seus moradores - aliadas a uma alimentação exclusivamente industrializada e ao estresse da cidade nova possa ter estreita relação com a incidência de doenças como o câncer.

As doenças cardiovasculares mencionadas foram doenças do coração, infarto e hipertensão arterial. Além da hipertensão, outras doenças, como colesterol alto, o excesso de peso (doenças endócrinas e metabólicas), o tabagismo (doenças neuropsiquiátricas), estão entre os principais fatores de risco das doenças não transmissíveis. Ainda, menciona o alcoolismo (doenças neuropsiquiátricas) que é fator de risco para as doenças sexualmente transmissíveis (DST).

O perfil epidemiológico, apresentado nos últimos quinze anos, de acordo com a base de dados de fonte secundária, do Departamento de Informática do Sistema Único de Saúde do Brasil (DATASUS), configura certa relevância às doenças dos aparelhos respiratório e circulatório e seus agravos, como também, a neoplasia (câncer) na classe de doença crônico-degenerativa. Os registros em relação à incidência de doenças neuropsiquiátricas e por causas externas não se destacaram dentre os dados oficiais, porém, nos relatos dos sujeitos da pesquisa isso se torna

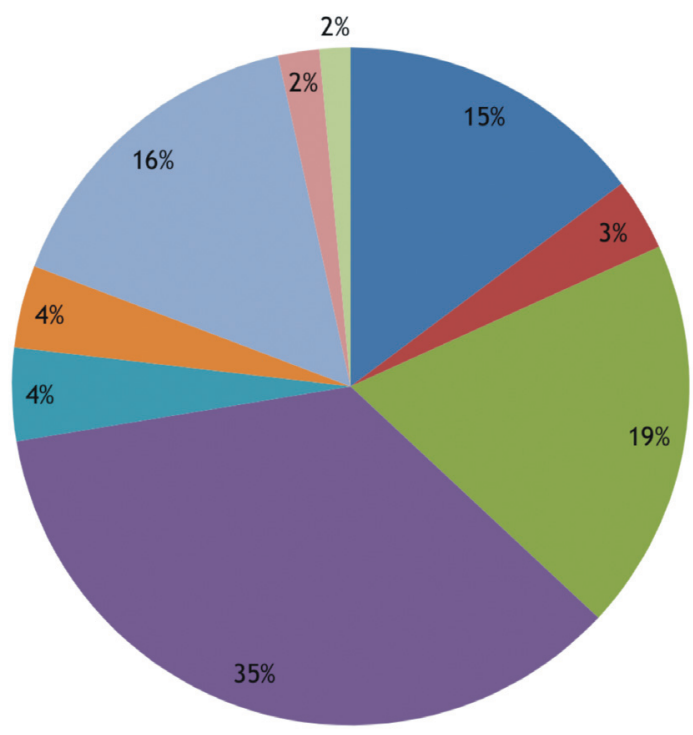

- Doenças Cardiovasculares D Doenças Endócrinas- Metabólicas

- Doenças Infectocontagiosas = Doenças Neuropsiquiátricas

n Doenças Respiratórias n Neoplasias (Câncer)

- Doenças Gastrointestinais
- Doenças da Pele e Tegumentos
- Causas Externas

Fig. 1 - Doenças mais comuns na cidade velha por categoria e frequência (Fonte: Pesquisa direta. Elaborado por: Astolphi -2015).

Fig. 1 - Most common diseases in the old town per category and frequency (Source: Direct search. Prepared by: Astolphi -2015). 
evidente a exemplo da entrevista 125, anteriormente descrita, que mostra uma considerável frequência.

De forma geral às alterações do perfil epidemiológico da cidade de Nova Ponte (escala local), apresentado a partir da análise dos dados coletados de fonte primária, encontra ressonância com a mudança do perfil epidemiológico do Brasil (escala nacional).

De acordo com o Ministério da Saúde (Brasil, 2004) a mudança do perfil epidemiológico no país, nos últimos vinte anos, pode ser expressa pela permanência das doenças do aparelho circulatório como principal causa de morte, pela redução da importância das doenças infecciosas e parasitárias e, principalmente, pela evolução das neoplasias e das causas externas.

\section{Conclusão}

As reflexões geradas nesse estudo apontam para uma relação estreita entre o uso do território, a partir da implantação de projetos de investimentos, do deslocamento compulsório da população, alterando o seu "modus vivendi", com mudanças no processo saúde-doença, este entendido nos seus aspectos biopsicossociais, econômico, cultural e ambiental.

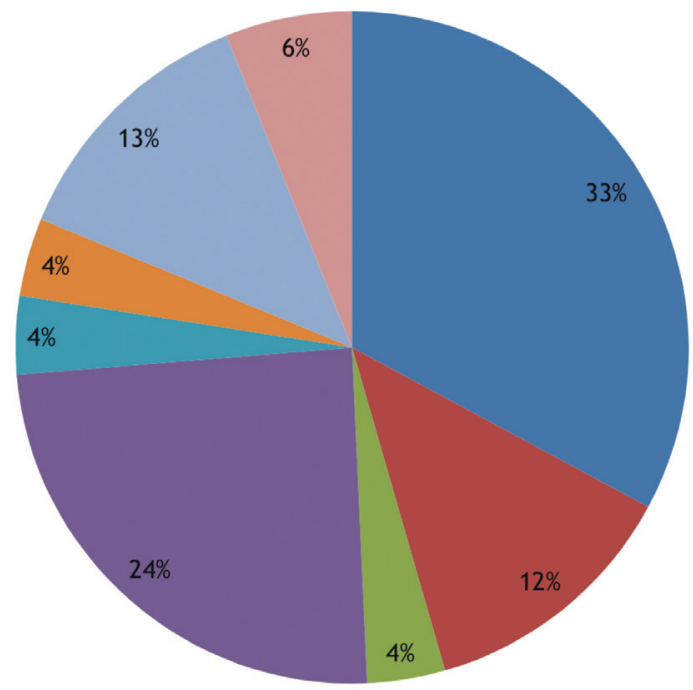

- Doenças Cardiovasculares - Doenças Neuropsiquiátricas n Neoplasias (Câncer)
- Doenças Endócrinas- Metabólicas - Doenças Osteomusculares - Causas Externas
- Doenças Infectocontagiosas

- Doenças Respiratórias

Fig. 2 - Doenças mais comuns na cidade nova por categoria e frequência (Fonte: Pesquisa direta. Elaborado por: Astolphi -2015).

Fig. 2 - Most common diseases in the new town per category and frequency (Source: Direct search. Prepared by: Astolphi -2015).
Os riscos à saúde, foram considerados como parte do processo de adoecimento da população, alterando o perfil epidemiológico, este entrecortado pela ação de implantação de um grande projeto de investimento, com a inundação da cidade velha e o deslocamento de toda a população para a cidade nova. Este fato, marcado pelos condicionantes socioeconômico, ambiental e cultural, interferiu no modo de vida (ou modus vivendi) da população e promoveu o uso do território, no movimento de desterritorialização e reterritorialização.

O enfoque dos riscos a saúde, corroborado pela análise de riscos socialmente construídos, possibilita inferir que a mudança para a cidade nova trouxe, a princípio, ganho financeiro em termos de edificação, de infraestrutura (tratamento de água e de esgoto, pavimentação, coleta de lixo, entre outras) que mitigaram doenças de veiculação hídrica (exemplos: cólera, hepatite A e doenças diarréicas agudas de várias etiologias, vírus e parasitas) e de precárias condições de moradia (exemplo: doença de Chagas). No entanto, produziram novas doenças associadas às transformações do território, como de causas externas (acidentes automobilísticos, com arma branca, arma de fogo, atropelamento), no cerne dos riscos sociais, como a violência, a criminalidade e o tráfico de drogas, resultantes em boa parte do chamado progresso, do desenvolvimento e da desigualdade social.

Torna-se pertinente a constatação de que doenças relacionadas ao campo neuropsiquiatrico, como quadros de depressão, de estresse, de dependência de álcool e outras drogas, constituem riscos a saúde, na medida em que se relacionam com isolamento social, pressões cotidianas, mudanças de hábito de vida, ainda mais quando, tem no seu nascedouro o dilaceramento das relações de proximidade física e afetiva com familiares e vizinhança, num convívio estreito e genuíno, de uma vida pacata e sossegada, realidade alterada pela desterritorialização.

A prática da vida cotidiana transformada pela chegada do grande empreendimento, sinônimo de progresso local e regional, demonstra uma significativa alteração na relação do morador com o território, seja, pelo modo de produção, pelo convívio social, pela aculturação, pelo processo de saúde-doença, que caracterizou a reterritorialização no município de pequeno porte, que vivia numa relação mais estreita com o território físico e simbólico da cidade velha.

As alterações empreendidas no território, local fértil para a produção de movimentos de toda ordem e grandeza, guarda relação estreita com os processos biopsicossociais que acometem os indivíduos e, por conseguinte grupos e a população em geral. As relações tecidas nas dimensões política, econômica e cultural no cotidiano do território e tensões produzidas podem ser associadas às formas de adoecimento da população. 
A contribuição da pesquisa reside no fato de suscitar o debate sobre o trinômio território-hidrelétrica-saúde, numa visão sistêmica do homem com o espaço vivido e de estabelecer possíveis relações de efeitos sociais do território usado com os riscos à saúde. Pretende-se também plantar a semente que instigou os pesquisadores a lançarem um olhar investigativo e desafiador na compreensão das relações existentes entre os grandes projetos, a população submetida e os riscos à saúde.

\section{Referências Bibliográficas}

Becker, B. K. (2012). Reflexões sobre hidrelétricas na Amazônia: água, energia e desenvolvimento. Boletim do Museu Paraense Emílio Goeldi- Ciências Humanas, vol. 7/ n. ${ }^{\circ}$ 3, Belém, p.783-790.

Birman, J. (1991). A physis da saúde coletiva. Physis Revista Saúde Coletiva, vol.1 / $\mathrm{n}^{\circ} 1$, Rio de Janeiro, p. 7-11.

BRASIL, MINISTÉRIO DA SAÚDE (2004). Secretaria de Vigilância em Saúde. Departamento de Análise de Situação de Saúde. Saúde Brasil 2004 uma análise da situação de saúde. Brasília: Ministério da Saúde.

BRASIL, MINISTÉRIO DA SAÚDE (2006). Secretaria de Atenção à Saúde. Departamento de Regulação, Avaliação e Controle. Sistemas de Informações Ambulatoriais do SUS (SIA/SUS): manual de orientações técnicas/Ministério da Saúde, Secretaria de Atencão à Saúde, Departamento de Regulação, Avaliação e Controle. Brasília: Editora do Ministério da Saúde.

BRASIL, MINISTÉRIO DA SAÚDE (2013). Secretaria de Atenção à Saúde. Departamento de Regulação, Avaliação e Controle. Coordenação Geral de Sistemas de Informação - 2010: manual técnico operacional do sistema de informação hospitalar orientações técnicas. Versão 01.2013. Brasília: Editora do Ministério da Saúde.

Buss, P. M. (2002). Promoção da Saúde da Família. Ministério da Saúde. Biblioteca Virtual em Saúde 2002. Disponível em: bvsms.saude.gov. br/bvs/is_digital/is_0103/IS23(1)021.pdf. Acesso em11 de abril de 2014];

Calabi, A. S., Fonseca, E. G. da, Saes, F. A. M. de, Kindi, E., Lima, J. L., Leme, M. I. P., Reichstul, H. P. (1983). A energia e a economia Brasileira: interações econômicas e institucionais no desenvolvimento do setor energético no Brasil. Pioneira. Fundação Instituto de Pesquisas Econômicas. São Paulo, 250 p.

Castiel, L. D., Guilam, M. C. R., Ferreira, M. S. (2010). Correndo o risco: uma introdução aos riscos em saúde. Editora Fiocruz (coleção Temas em Saúde). Rio de Janeiro, 136 p.

COMPANHIA ENERGÉTICA DE MINAS GERAIS - CEMIG (1995). Projeto Executivo, Relatório de Integração e Estudos Ambientais. Leme Engenharia Ltda. Belo Horizonte, $86 \mathrm{p}$.

Fernandes, P. F. C. B. C. (2013). Medicina Baseada em Evidências. In: Rouquayrol, M. Z., Gurgel, M. (org.) - Epidemiologia \& Saúde, MedBook, Rio de Janeiro; (7 $7^{\mathrm{a}}$ edição), p.177-187.

Gil, A. C. (1999). Métodos e técnicas de pesquisa social. Atlas. São Paulo, (5. ${ }^{a}$ edição), 206 p.
Haesbaert, R. (2004). O mito da desterritorialização: do "fim dos territórios" à multiterritorialidade. Bertrand Brasil. Rio de Janeiro, 395 p.

Last, J. M. (Eds.) (1989). A Dictionary of Epidemiology. Oxford Universty Press. Nova York, 312 p.

Lemos, J. C., Lima, S. do C. (2002). A geografia médica e as doenças infecto-parasitárias. Revista Caminhos de Geografia, vol. $3 / \mathrm{n}^{\circ}$ 6, Uberlândia, p. 74-86.

Lima, H. R., Silva, V. de P. da (2011). Divergências e convergências nas políticas de sustentabilidade de empreendimentos hidrelétricos: efeitos socioespaciais no Rio Araguari-Minas Gerais Brasil. Revista Geográfica de América Central, número especial EGAL, Costa Rica, p. 1-22.

Martins, J. de S. (1993). A chegada do estranho. Hucitec. São Paulo, 179 p.

Mendes, E. V. (2009). As redes de atenção à saúde. Autêntica Editora (ESP-MG). Belo Horizonte, 848 p.

Minayo, M. C. de S. (2007). O desafio da pesquisa social. In: Minayo, M. C. de S., Deslandes, S. F., Gomes, R. (Org.) - Pesquisa Social: teoria, método e criatividade, Vozes, Petrópolis; $\left(25^{\mathrm{a}}\right.$ edição revista e atualizada), p. 9-29.

Nunes, E. D. (1994). Saúde coletiva: história de uma ideia e de um conceito. Saúde e Sociedade, vol. 3 / n. ${ }^{\circ}$ 2, São Paulo, p. 5-21.

Porto, M. F. de S., Finamore, R. (2012). Riscos, saúde e justiça ambiental: o protagonismo das populações atingidas na produção de conhecimento. Ciência \& Saúde Coletiva, vol. 17/ n. ${ }^{\circ}$ 6, Rio de Janeiro, p. 1493-1501.

Raffestin, C. (1993). Por uma Geografia do poder. Tradução de Maria Cecília França. Ática, São Paulo, 269 p.

Rouquayrol, M. Z., Goldbaum, M., Santana, E.W.de P. (2013). Epidemiologia, História Natural e Prevenção de Doenças. In: Rouquayrol, M. Z.; Gurgel, M. (org.) - Epidemiologia \& Saúde, MedBook, Rio de Janeiro; ( $7^{a}$ edição), p.11-24;

Santos, B. de S.(2012). Moçambique: a maldição da abundância?, [BUALA]. Disponível em: http:// www. buala.org/pt/a-ler/mocambique-amaldicao-da-abundancia. [Acesso em: $11 \mathrm{de}$ abril de 2014];

Santos, M. (1999). A Natureza do Espaço: espaço e tempo, razão e emoção. Hucitec, São Paulo, 258 p.

Silva, F. B. (2007). Planejamento regional / territorial: a interface entre os planos diretores de aproveitamentos hidrelétricos e os planos diretores municipais (Dissertação /Mestrado), UFU, Uberlândia-MG, 199 p.

Silva, V. de P. (2013). Grandes empreendimentos, cidade e transformações espaciais: uma discussão teórica. In: Rodrigues, S. C., Mercante, M. A. (Org.) - Avaliação socioambiental do domínio dos cerrados e pantanal: métodos e técnicas, Composer (UFU e Anhanguera-UNIDERP), Uberlândia, p.111-123.

Vainer, C. B., Araújo, F. G. B. (1992). Grandes projetos hidrelétricos e desenvolvimento regional. CEDI. Rio de Janeiro, 88 p.

Veyret, Y. (2007). Os riscos: o homem como agressor e vítima do meio ambiente. Tradução de Dilson Ferreira da Cruz. Contexto, São Paulo, 319 p. 

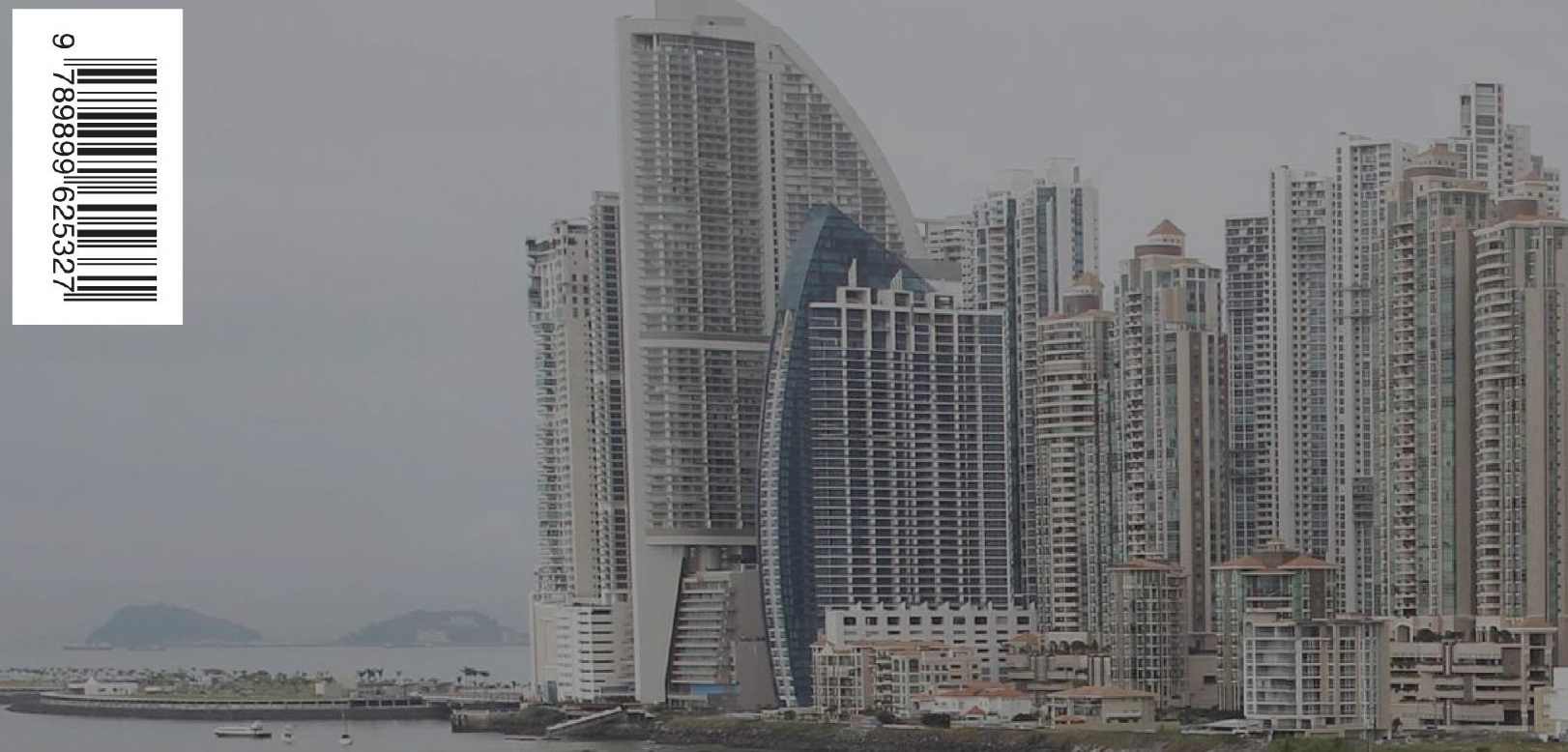

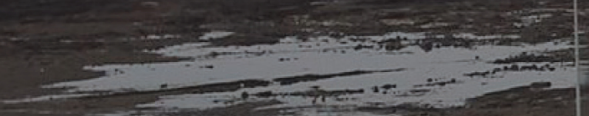

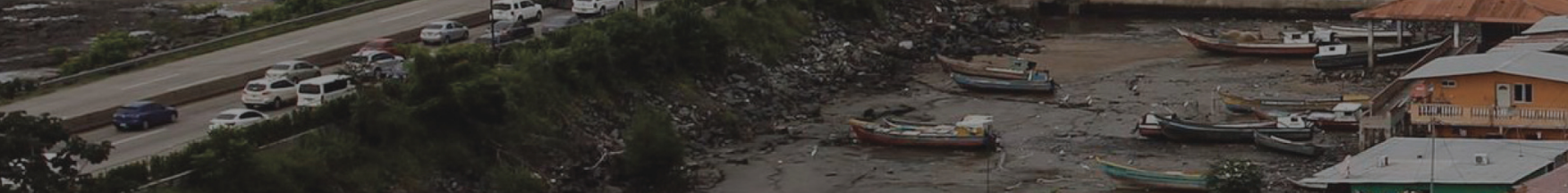

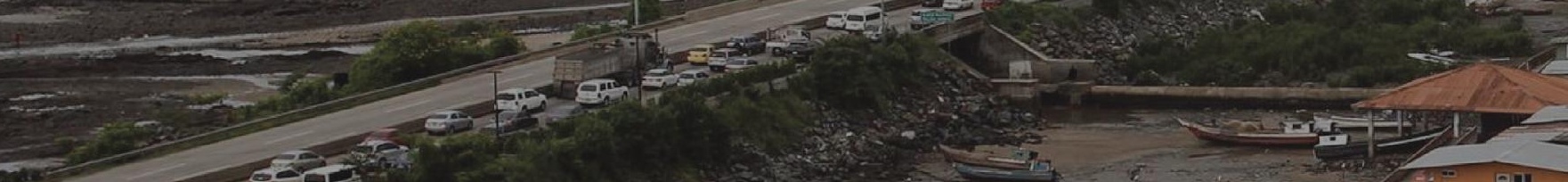
inse- $n=$ Riscos I I I

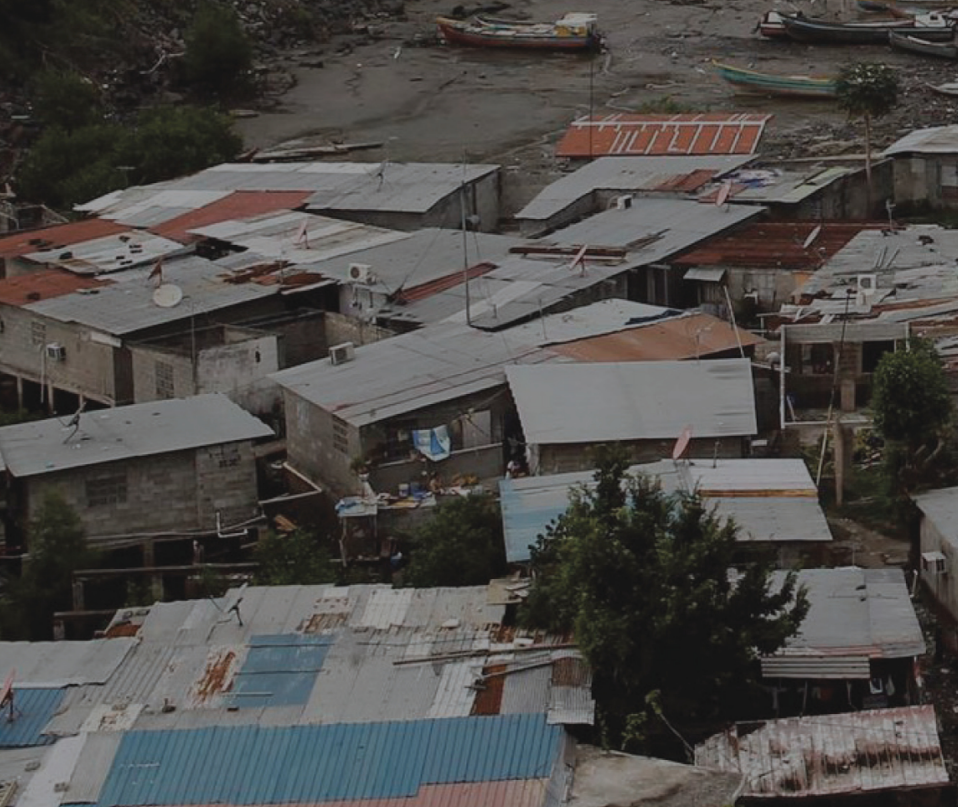

